IOS Press

\title{
Rotating cross-arm trellis technology for blackberry production
}

\author{
Fumiomi Takeda*, David Michael Glenn and Thomas Tworkoski \\ Appalachian Fruit Research Station, Agricultural Research Service, US Department of Agriculture, \\ Kearneysville, WV, USA
}

Received 26 July 2012; accepted 5 October 2012

\begin{abstract}
The rotating cross-arm (RCA) technology combines a unique trellis design and cane training protocol. Developed over the last two decades, this technology is beginning to have an impact on the blackberry (Genus Rubus, subgenus Rubus) industry in the United States (US). It has been successfully transferred to growers in more than 21 states in the last two years and contributed to increasing the blackberry acreage by about $\sim 100$ ha in the eastern US. Our research and development effort on the RCA technology has shown that 1) winter injury can be reduced by modifying the crop environment and production techniques, 2) white drupe formation can be reduced when fruit is positioned away from direct sunlight, and 3) harvest efficiency is improved when the fruit positioned on one side of the row. Our research has also shown that RCA technology can be used to generate several times more one-node floricane cuttings and long-cane plants than traditional propagation methods. The enclosure technique improved rooting of some cultivars, but there were recalcitrant cultivars like 'Apache'. Auxin analyses suggested a possible link between IAA concentrations and root induction in floricane cuttings. Consistent production of blackberries was achieved in areas with minimum winter temperatures below $-20^{\circ} \mathrm{C}$ with the RCA technology. This technology allows the canes to be positioned close to the ground in winter and covered with a floating rowcover. An unexpected result of this winter protection system was some leaves on the floricane remained green throughout the spring and were photosynthetically functional in spring.
\end{abstract}

Keywords: Rubus, winter injury, trellis, primocane, floricane, drupe, sun damage, photosynthesis, auxin, long-cane plants, cane training, canopy management, vegetative propagation

\section{Introduction}

Conventional blackberry production in North America requires high labor and chemical inputs, making production more difficult for blackberry growers in the United States (US) to maintain a profitable operation with ever-increasing competition and market share by countries like Mexico, which is the source of nearly $70 \%$ of fresh blackberries sold in the US [1]. This has renewed interest in improving cropping efficiency and production systems in order to increase fruit production and quality at times when blackberry shipments from Mexico are low. According to a recent survey [1], the major areas for fresh blackberry production areas are in the western (California and Oregon) and southern (Arkansas, Georgia, and Texas) US. However, in the northcentral and northeastern regions of the US, blackberry production has been limited due to a number of environmental constraints such as regular occurrence of lethal low winter temperatures $<-20^{\circ} \mathrm{C}$ (Fig. 1) and spring freezes $\left(<-4^{\circ} \mathrm{C}\right.$ ) occurring from the time of budbreak in March to bloom in May. Extremely high summer temperatures and solar radiation levels cause drupes to turn white and reduce pack-out in some cultivars. These production issues in part have been addressed with innovations in production

*Corresponding author: Fumiomi Takeda, USDA-ARS, Appalachian Fruit Research Station, 2217 Wiltshire Road, Kearneysville, WV 25430, USA. Tel.: +1 304725 3451; E-mail: fumi.takeda@ars.usda.gov. 


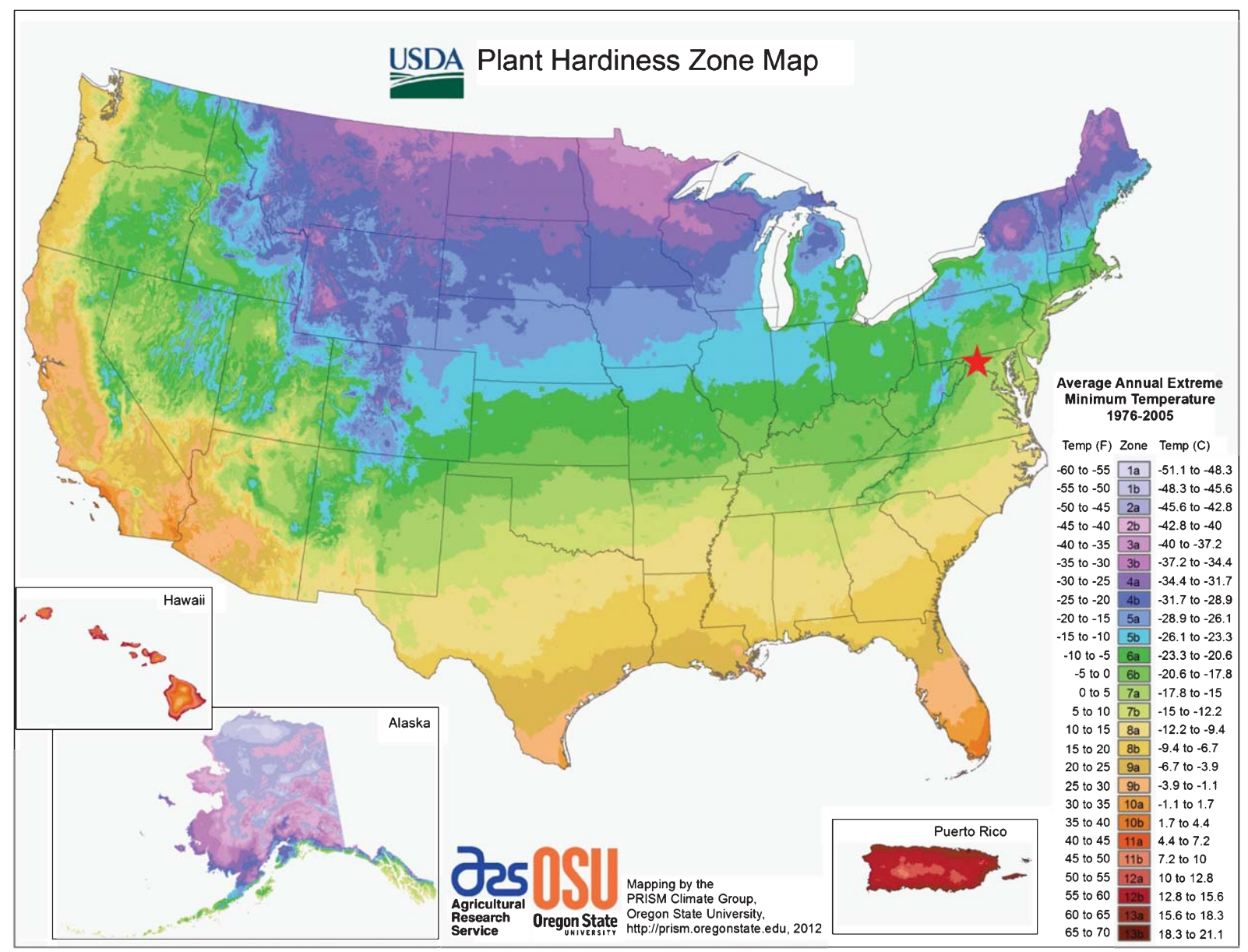

Fig. 1. The 2012 USDA Plant Hardiness Zone Map (http://planthardiness.ars.usda.gov/PHZMWeb/). Little or no commercial blackberry production in areas in dark green, blue, and purple colors exists currently. These areas are the northcentral and northeastern United States where average extreme annual minimum temperatures in the -20 to $-25^{\circ} \mathrm{C}$ or below are common. The location of Appalachian Fruit Research Station is indicated by a red star.

practices and plant canopy manipulation, and with proper cultivar selection [2-6]. These improvements have fostered expansion of commercial blackberry production and have helped mitigate environmental factors that limit profit potential.

Interest in growing blackberries has increased among the US farmers looking for alternative crops that capture niche markets and have potential for high returns on investment. Blackberry acreage in the US increased $25 \%$ from 1995 to 2005 to about 4,800 ha. Over half of this acreage is in Oregon and the Pacific Northwest where the production is mainly for the processing industry. The top five states for fresh-market blackberry production are Oregon (300 ha), California (280 ha), Texas (270 ha), Arkansas (240 ha), and North Carolina (180 ha). By 2015, the total blackberry production acreage is expected to increase to 5,700 ha (B. Strik, personal communication). Much of the new acreage (900 ha) will be primarily for fresh-market production. In vast area of northeastern and northcentral US (i.e., Pennsylvania, Ohio, New York, Massachusetts, West Virginia, Maryland, New Jersey, Delaware, Indiana, Illinois, Iowa, Kansas, and Kentucky), the total acreage for blackberries is currently estimated at less than 290 ha [1] with much of the fruit sold locally. Nearly 100 ha of this acreage in the northcentral and northeastern US have been established in the last 3 years (Fig. 2) using a novel trellis design called the rotating cross-arm (RCA) trellis. The commercial RCA trellis (Fig. 3) is constructed of fiberglass reinforced plastic components manufactured by the pultrusion process. It 


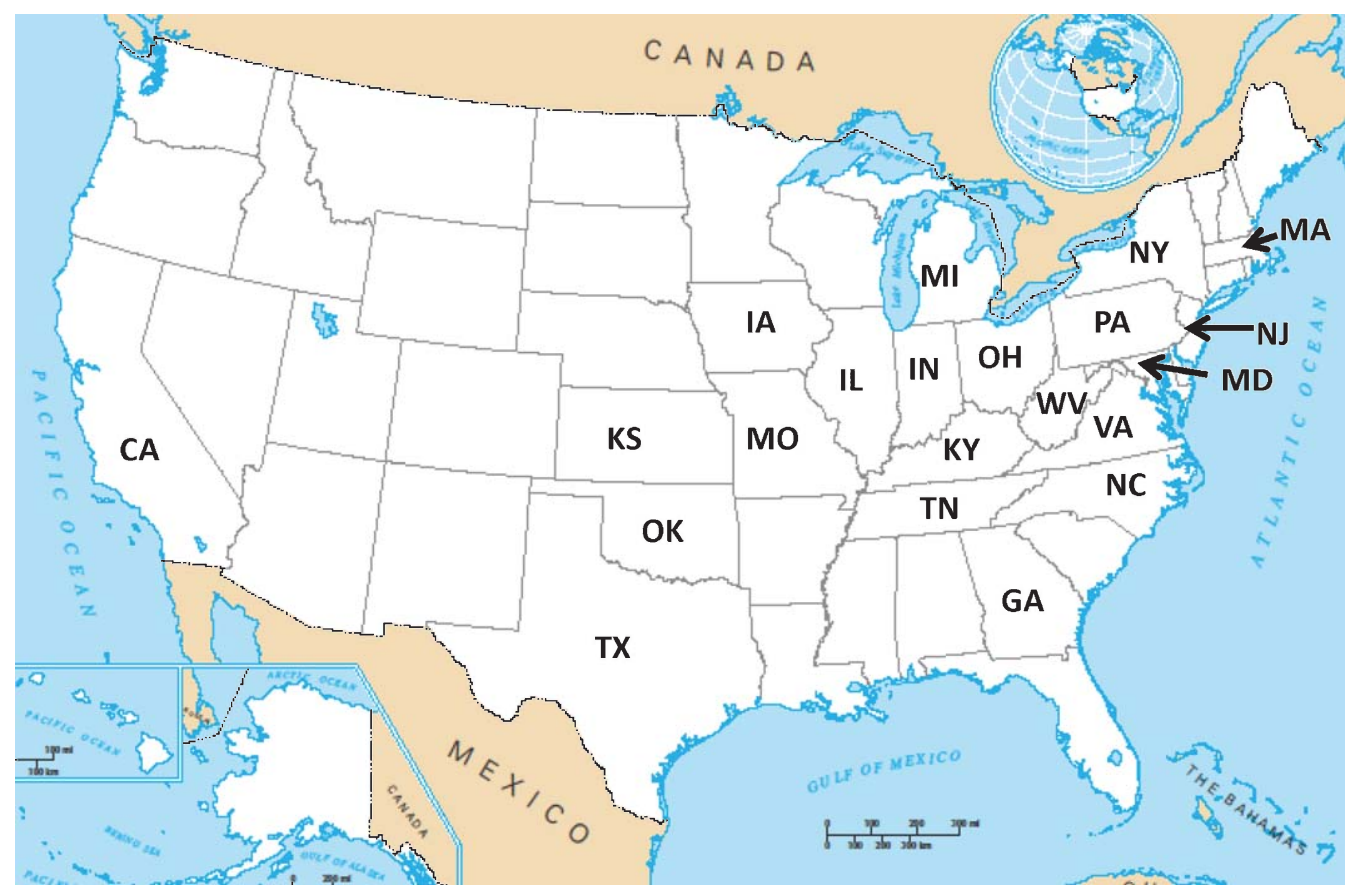

Fig. 2. States with commercial size ( $>0.5 \mathrm{ha}$ ) blackberry plantings with the rotating cross-arm trellis and cane training system developed by USDA-ARS research are highlighted in white. This technology is being used by blackberry growers in the vast region encompassing the central and eastern US. California (CA), Georgia (GA), Illinois (IL), Indiana (IN), Iowa (IA), Kentucky (KY), Maryland (MD), Massachusetts (MA), Michigan (MI), Missouri (MO), New Jersey (NJ), New York (NY), North Carolina (NC), Ohio (OH), Oklahoma (OK), Pennsylvania (PA), Texas (TX), Tennessee (TN), Virginia (VA), and West Virginia (WV).

has a post which is $\sim 50 \mathrm{~cm}$ high with two plates attached at the top. A long and a short cross-arm are assembled to the plates. The arms are secured to the plates with detent pins and are rotatable. There are trellis wires on both arms for securing lateral canes. In addition, two wires are threaded through holes in the plates. These wires are used for primocane cane training and repositioning the floricanes in late fall or early winter. The unique features of cane training and the RCA trellis design allow the plant canopy can be rotated easily from vertical in summer to horizontal in winter and back again to vertical in spring without breaking canes.

Production of blackberries is limited in the northcentral and northeastern US, classified as Plant Hardiness Zones 5 and 6, according to the 2012 USDA Plant Hardiness Zone Map [7], where the minimum temperatures below $-23^{\circ} \mathrm{C}$ are common during the winter months (Fig. 1). In these colder areas, blackberry plants produce vigorous primocanes each growing season, but the buds and canes develop symptoms of low temperature injury and do not produce fruit in most years. While four-season high tunnels could be used to produce blackberry in areas with low winter temperatures (Marvin Pritts, personal communication), the high cost ( $>\$ 100,000 / \mathrm{ha}$ ) of high tunnels and other permanent structures has prevented growers from adapting the system for winter protecting blackberry plant. A less expensive winter protection system with the RCA technology has proven to provide sufficient winter protection for blackberries [4-6] and offers an opportunity for farmers in the northcentral and northeastern states to produce blackberries for local and distant markets when more southern areas have finished production.

\section{Blackberry research at the Appalachian Fruit Research Station}

At the Appalachian Fruit Research Station, scientists have conducted a series of research projects since 1982 to develop improved blackberry production systems. They include: 


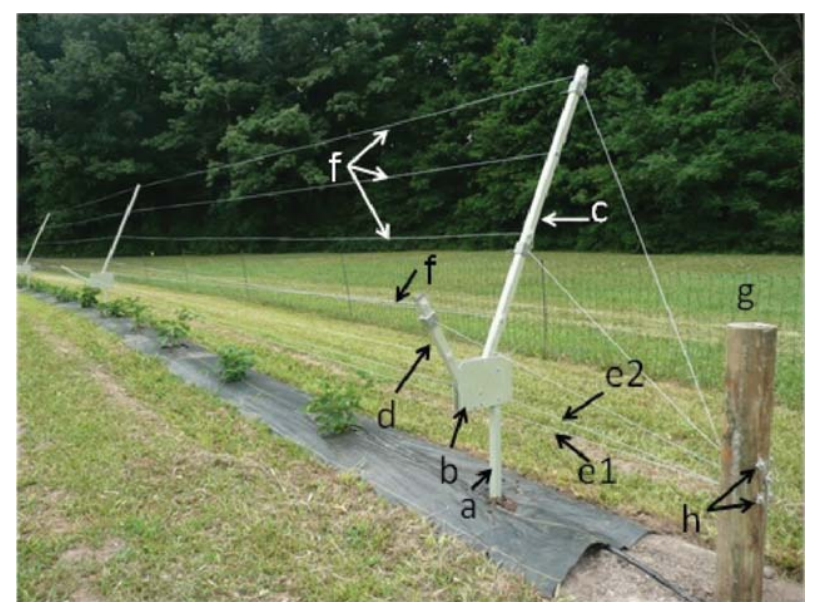

Fig. 3. The rotating cross-arm (RCA) trellis. The commercial version is constructed of fiberglass reinforced plastic components manufactured by the pultrusion process. A) The trellis consists of a post $(\sim 50 \mathrm{~cm})$ (a) which has two plates (b) attached at the top. A long (c) and a short (d) cross-arm is secured between the two plates with detent pins. Both cross-arms are rotatable. There are two cane training wires (e1 and e2) that are threaded through holes in the plates. Additional trellis wires (f) are threaded through both cross-arms and secured to end trellis assembly arms. The wires in the foreground are connected to a wooden tie-back post (g). The primocanes are placed on the training wire below the short cross-arm (e1). Wires terminate at the wooden tie-back post and on end trellis assembly arms on the first and last posts of each row with a "Quik-End tensioner (h) which has internal spring-loaded clamps. In winter the canes are pushed over to the training wire under the long cross-arm (e2). For details on primocane training see Fig. 3. Assembly and installation instructions are available from Trellis Growing Systems, Inc. (www.trellisgrowingsystem.com). Photo provided by Trellis Growing System, Inc.

1. Determining efficacy of novel cultural and chemical treatments to improve harvest mechanization and fruit quality $[2,3]$.

2. Developing production systems to mitigate low winter temperatures and reduce winter injury [4-6].

3. Manipulating the environment to accelerate and intensify floral bud initiation and subsequent reproductive development.

4. Better understanding of mechanisms controlling flower development and adventitious root formation in blackberry.

5. Identifying the effects of plant material source and environmental conditions on photosynthesis and long-cane production.

6. Developing the RCA trellis technology $[2,3]$.

Our research into alternative production systems and evaluation of novel germplasm materials is expected to provide new technology and create opportunities to produce berries for fresh market beyond the states along the Pacific Coast and southeastern US. Technology transfer efforts are expected to improve the viability of small fruit farming and the rural vitality. Currently the focus of this program is on the development of novel production systems and adaptation of newly released cultivars from several public blackberry breeding programs (e.g. University of Arkansas, USDA-ARS-Corvallis, and North Carolina State University) to various trellis cane training systems and winter protection methods.

\section{Cane training procedure for and canopy manipulation with the RCA trellis system}

In the conventional planting system on I- or T-trellis, blackberry (erect-type) transplants are established typically at less than 1-m apart. The primocanes of erect and semi-erect cultivars are trained to grow upright. Once the primocanes 


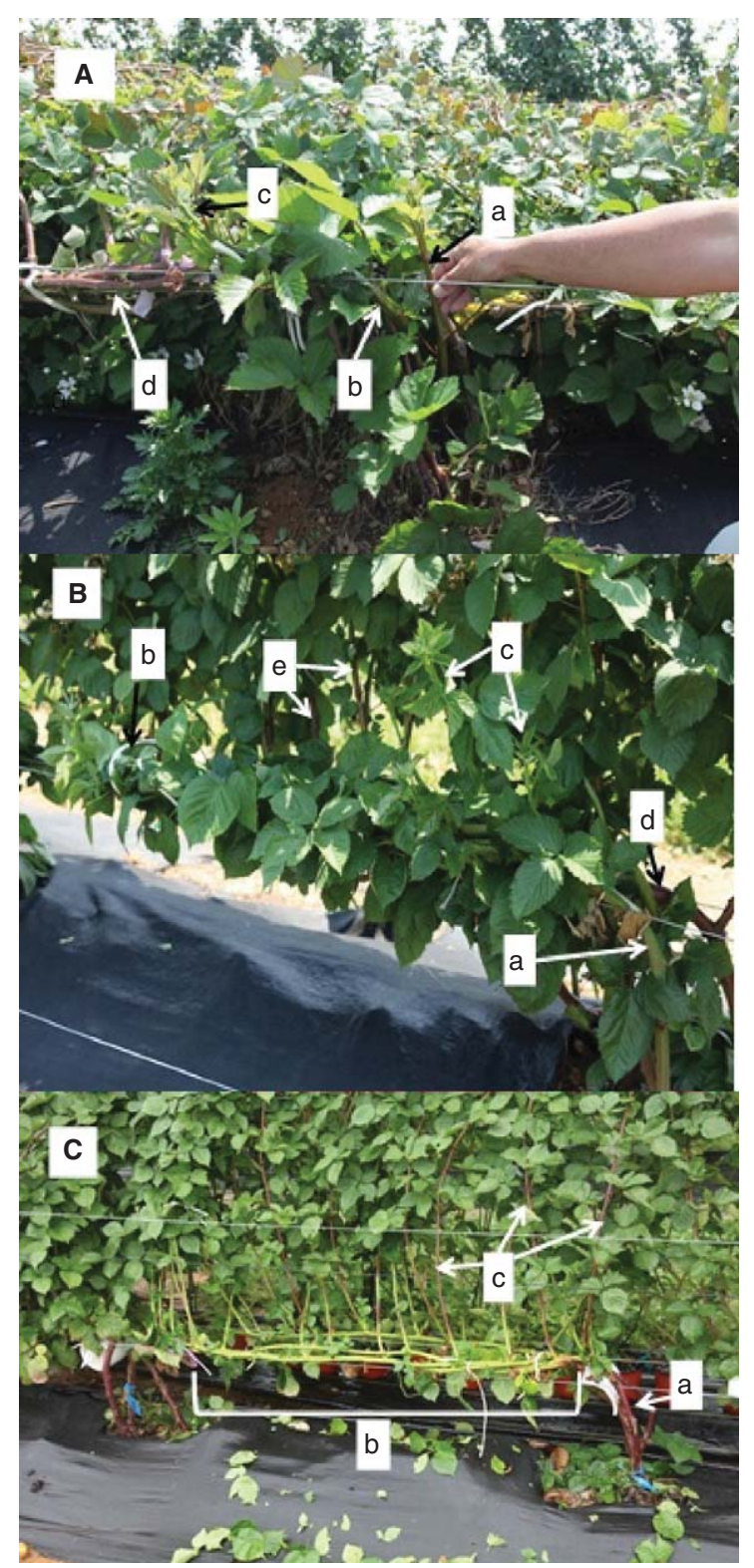

Fig. 4. Primocane training on the rotatable cross-arm (RCA) trellis in spring. A) Up to three primocanes are trained. The primocane (a) has grown about $15 \mathrm{~cm}$ above the training wire and is ready for bending. The succulent tip portion of the primocane is carefully bent and tied to the training wire as shown below the hand to force it to grow horizontally (b). The tip portion of horizontally trained primocanes must be tied periodically to the training wire or it will revert back to growing upward (c). The floricanes have been bundled and secured to the second training wire on the RCA trellis the previous fall (d). B) Bent primocanes (a) have grown about $1.7 \mathrm{~m}$ on the training wire. The portion must be secured on the training wire (b). Each primocane is tipped when the growing point reaches the adjacent plant. Secondary shoots (e.g. lateral canes) (c) develop from axillary buds on the primocanes. All lateral canes that emerge from nodes below the bend point are broken off. A floricane (d) and its lateral canes (e) that bear current year's crop can be seen behind this year's primocanes (a). C) Primocane growth on the RCA trellis in late summer. Three primocanes (a) have been secured to the training wire. The section of these canes that is oriented horizontally (b) has a length of about $1.7 \mathrm{~m}$. Note many lateral canes (c) have developed from this cane section. The leaves have been removed to reveal the origin of lateral canes. 
reach the topmost wire on the trellis, they are usually topped to promote lateral cane development. The lateral canes are pruned back to manageable length in winter. In the case of trailing cultivars, the primocanes are allowed to grow unsupported. In winter, the canes are gathered and bundled on the trellis wire. When the primocanes are handled as described for these static trellis systems, the canopy becomes difficult to manipulate or change cane orientation from vertical to more or less horizontal.

In the RCA trellis system, blackberry transplants are established at about 2-m between plants (Fig. 4). The primocanes are bent to grow horizontally on a training wire to the next plant, where they are tipped [2-6, 8, 9]. The height of the training wire can range from 0.4 to $0.6 \mathrm{~m}$. Our research has shown that several benefits can be derived from the cane bending procedure. The number of lateral branch canes per primocane increased from about 2.7 lateral branch canes $\cdot \mathrm{m}^{-1}$ primocane length in vertically trained system to nearly 8 lateral branch canes $\cdot \mathrm{m}^{-1}$ on horizontally trained primocanes. The lateral branch canes are pruned back to about $1.5 \mathrm{~m}$ length (the rotating cross-arm is 1.5-m long). The number of primocanes that can be attached to the training wire is typically less than four per plant, however, with more, longer lateral branch canes produced per primocane it means that on the plants trained to the RCA trellis have as much as $25 \mathrm{~m}$ cane length $\cdot \mathrm{m}^{-1}$ row distance compared to about $10 \mathrm{~m} \cdot \mathrm{m}^{-1}$ row distance for plants on the I- and T-trellises. Also, by tying longer lateral canes to wires on the RCA, a much narrower canopy is possible. The combination of the narrow canopy and the rotatable canopy, that is more or less vertical from late spring to fall and horizontal during the dormant period, offers opportunities to manipulate plant development and mitigate adverse environmental factors.

Without this special training, the bending of vertically trained blackberry floricanes to be oriented horizontally requires much force. In most cases, the upright canes cannot withstand the force applied and break. In contrast, we have developed a new cane training method in which the primocanes are trained to grow horizontally on a training wire about $40 \mathrm{~cm}$ above the ground [2-6]. The rotation of the cross-arms causes only the lateral canes that are secured to wires on the long cross-arms to be rotated. The explanation of why the canes trained on the RCA trellis according to the cane procedure as detailed in Fig. 4 can be rotated as much as 180 degrees without breaking the canes or need to apply an excessive force has been detailed in earlier publications [2-6]. In summary, the force on the cross arms to cause the canopy to rotate from vertical to horizontal causes the horizontally oriented distal section of floricane (b in Fig. 4C) to torque or twist against the basal, vertical section (a in Fig. 4C) of the floricane. Once the floricanes and lateral canes mature they become woody and the bent section can twist as the cross-arms are rotated.

With the RCA trellis and cane training system, the lateral canes are laid horizontally in late fall so that the plant canopy is as low as $0.5 \mathrm{~m}$ above the ground (Fig. 5A). Inclination of the lateral canes close to the ground creates a plant shape conducive for the placement of winter protection material over them (Fig. 5B). With lateral canes oriented horizontally from budbreak to bloom, greater than $96 \%$ of flowering shoots that emerged from the axillary buds on lateral canes develop upward (Fig. 5A). Once flowering has occurred, the cross arms can be raised beyond vertical, resulting in almost all the fruit being positioned on one side of the row (Fig. 5B).

\section{Growing blackberries in areas with low winter temperatures}

In the northcentral and northeastern US low $\left(<-21^{\circ} \mathrm{C}\right)$ temperatures in the winter are common and fruit pack-out can be significantly reduced by winter kill or injury. We hypothesized that the manipulation of blackberry plant canopy can be used to mitigate the effects of adverse environmental conditions. We used the RCA trellis system and cane training method that had been developed for mechanical fruit harvesting research [2, 3] for mitigating low winter temperatures. The RCA trellis and cane training system allows the canopy to be laid close to the ground in winter so that a rowcover could be placed on top of the canopy (Fig. 6) and moderate the temperature [4, 6].

For example, 'Siskiyou' a western trailing blackberry cultivar developed in Oregon (USDA Plant Hardiness Zone 8b) suffers winter injury when the temperature drops below $-11^{\circ} \mathrm{C}$ (personal observation). At the Appalachian Fruit Research Station which is in USDA Plant Hardiness Zone 6b (Fig. 1), trailing type, such as 'Siskiyou' and 'Black Diamond' [10], has been successfully produced more than $5.5 \mathrm{~kg} / \mathrm{plant}$ even after winters with temperatures below $-18^{\circ} \mathrm{C}$, if they were grown using the RCA trellis and cane training system and with a row cover $\left(50 \mathrm{~g} \cdot \mathrm{m}^{-2}\right)$ in winter. For better results, growers are instructed to rotate the canopy close to the ground in late fall and install a rowcover, but leave one side of the rowcover off the ground until extremely low temperatures (e.g. below $-12^{\circ} \mathrm{C}$ 

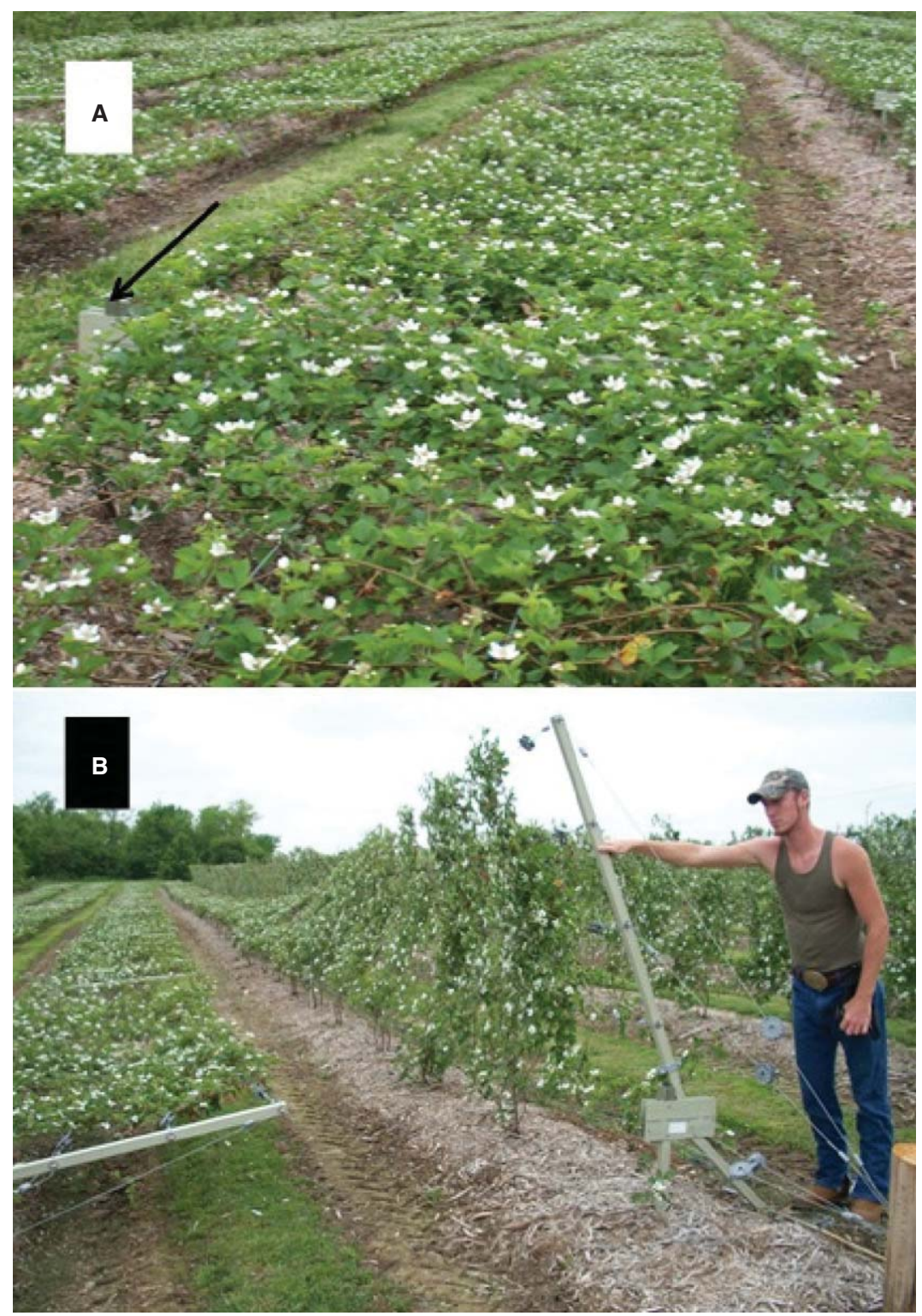

Fig. 5. Blackberry plants on the rotatable cross-arm trellis at bloom. A) The long cross-arms are oriented horizontally. Note the top of the post (arrow) on left side. The lateral canes that were secured to the wire on the long cross-arms have produced flower shoots and all have grown upward. Flower shoots that develop from axillary buds oriented down on the lateral canes will curve and grow upward between lateral canes. B) Soon after all the flower shoots have a few open flowers the cross-arms can be rotated upward and beyond vertical. By this time, the rachis (inflorescence axis) is woody and will not curve upward. The upward rotation of the cross-arms positions the fruit on one side of the row.

for erect blackberries and below $-9^{\circ} \mathrm{C}$ for trailing blackberries) are forecasted. The rowcover may require lifting on one side in late winter and early spring when the daytime high temperatures above $13^{\circ} \mathrm{C}$ are in the forecast for three or more consecutive days. If the rowcover is left in the field after budbreak then it can be rolled back over the low-profile plant canopy to the flower shoot in case of spring frost. In Spring 2012, a grower in Iowa reported that 'Triple Crown' blackberry plants trained to the RCA trellis and covered with a rowcover $\left(165 \mathrm{~g} \cdot \mathrm{m}^{-2}\right)$ showed no signs of freeze damage to their flower shoots whereas on those plants that were not covered shoots had become 


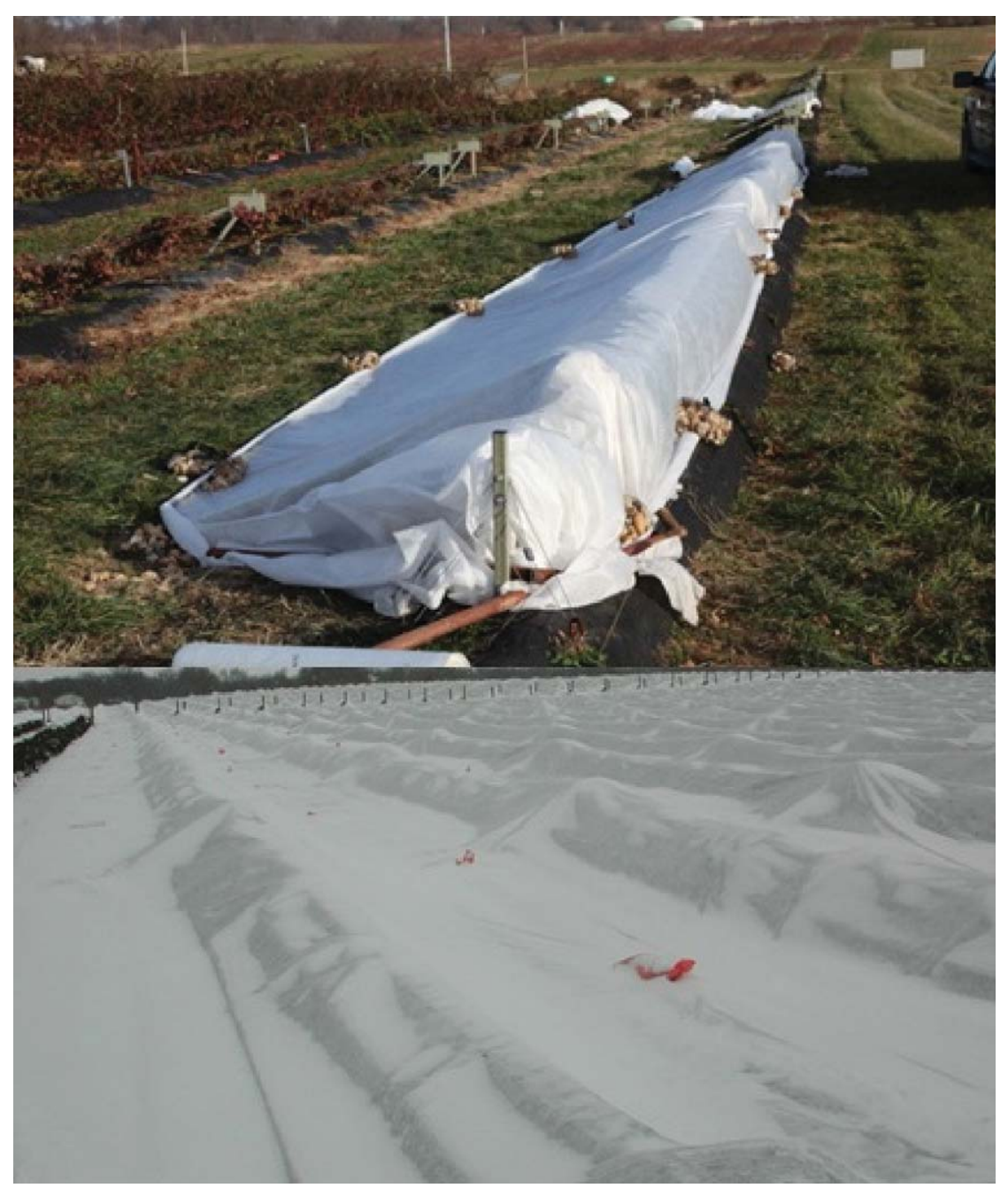

Fig. 6. Winter protection of blackberry plants trained on the rotatable cross-arm trellis. A) Research plots at the Appalachian Fruit Research Station. In the row on left, the cross-arms have been rotated down to position the lateral canes close to the ground. The plot in the foreground has been covered with a floating rowcover and the perimeter secured with bags of stones. B) A large commercial blackberry planting in Circleville, $\mathrm{OH}$. Rows that are about 100-m long have been covered with a floating rowcover. Snow accumulation provides additional insulation. Note that there are two rows on the far left side that have not been covered.

blackened (R. Barnes, personal communication). In areas with extremely cold winters, growing blackberries using the RCA trellis technology and rowcover application appears to be a better option than growing blackberries in high tunnels (e.g. lower capital investment, faster return on investment, and capacity for larger scale of operation) [4-6].

\section{Relationships between unique canopy architecture and fruit quality}

In some blackberry production areas of the country intense sunlight and high temperatures in the summer can cause poor fruit quality. In particular, the white drupe disorder (Fig. 7A) in 'Apache' blackberry can cause significant reduction in pack-out. In 2010, sunburn injury was reported to have accounted for $30 \%$ loss in fresh market pack-out in this cultivar in the southeastern US. The disorder has been attributed to high solar radiation, high ultra-violet 

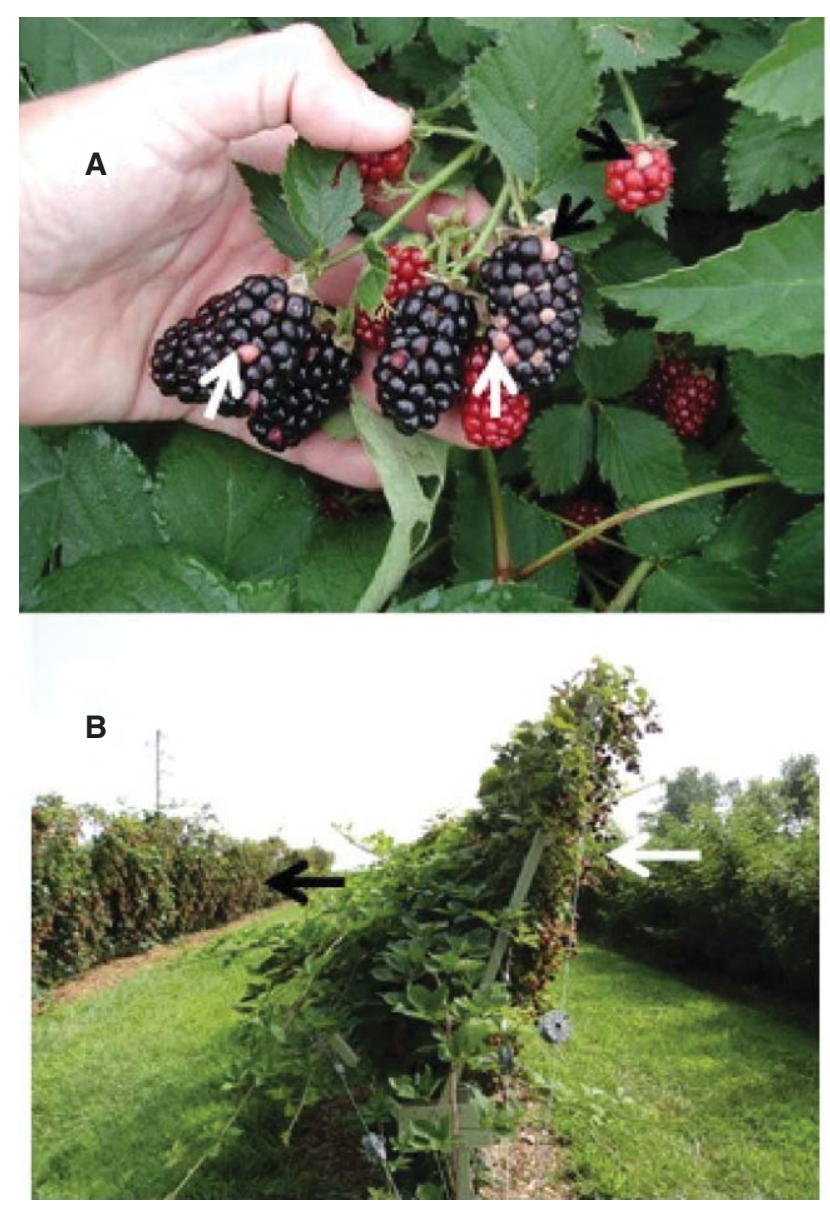

Fig. 7. Mitigating adverse environmental conditions with canopy management. A) White drupe (arrows) formation in 'Apache' blackberry. B) By using the rotating cross-arm trellis and orienting the rows in east-west direction fruit could be positioned on the north-side of the row (arrow) and away from exposure to direct sunlight. Photos provided by Dr. John Clark and Trellis Growing System, Inc., respectively.

radiation, and high temperature after rain. Biotic factors, such as feeding damage caused by flower thrips (Frankliniella occidentalis and stink bug (Hemiptera: Pentatomidae) have been suggested to bring about white drupe formation, but no published data are available. Certainly, there is a genetic factor attributable to this disorder as it develops in some cultivars (e.g. 'Apache') and not in others. However, contribution of abiotic factors such as high solar radiation levels or temperatures as a causal factor of this disorder should not be discounted.

The unique canopy configuration that was achieved with the RCA trellis and cane training system has provided additional benefits on fruit quality. The RCA trellis technology allows fruit to be positioned on one side of the row (Fig. 7B). If the rows are oriented east-west, fruit can be positioned on the north side of the row and not exposed to direct sunlight in the morning or afternoon. If the rows are oriented north-south, the fruit would be exposed either to morning or afternoon sun depending on which side the fruit is positioned. Our findings from the 2011 study with 'Apache' blackberry (Table 1) indicated that the incidence of white drupe formation was similar whether fruit was on east or west side of the row. However, direct exposure to sunlight either in the morning or afternoon significantly increased the number and severity of white drupe formation compared to the fruit in the shade. The skin temperature was as much as $8^{\circ} \mathrm{C}$ higher in berries exposed to sun than those in the shade. In 2010 , a cooperator in California reported, that by using the RCA trellis and cane training system, harvest efficiency was improved by $30 \%$ and, more significantly, fruit cull (berries with white drupes) was eliminated when the fruit was positioned on 
Table 1

The effect of fruit location (east vs. west side of rows oriented north-south) and exposure to sun (perimeter vs. interior of canopy) on white drupe formation in 'Apache' blackberry. The results are expressed as percentages of mature fruit that harvested in July with 0, 1-5, 6-10, or over 10 drupes that had become white

\begin{tabular}{|c|c|c|c|c|c|c|c|c|c|c|c|c|}
\hline \multirow[t]{2}{*}{ Treatment } & \multicolumn{4}{|c|}{ Week 1} & \multicolumn{4}{|c|}{ Week 2} & \multicolumn{4}{|c|}{ Week 3} \\
\hline & 0 & $1-5$ & $6-10$ & $>10$ & 0 & $1-5$ & $6-10$ & $>10$ & 0 & $1-5$ & $6-10$ & $>10$ \\
\hline East & 59 & 35 & 6 & 1 & 51 & 40 & 8 & 2 & 58 & 17 & 5 & 20 \\
\hline West & 51 & 33 & 7 & 8 & 47 & 39 & 9 & 5 & 63 & 23 & 9 & 6 \\
\hline Exposed & 29 & 51 & 12 & 8 & 26 & 53 & 15 & 7 & 30 & 31 & 13 & 26 \\
\hline Shaded & 82 & 18 & 1 & 0 & 72 & 26 & 2 & 0 & 91 & 10 & 0 & 0 \\
\hline $\mathrm{P}>\mathrm{F}$ & & & & & & & & & & & & \\
\hline Location & $\mathrm{NS}^{\mathrm{z}}$ & NS & NS & $* *$ & NS & NS & NS & NS & NS & NS & $*$ & $*$ \\
\hline Shade & $* * *$ & $* *$ & $*$ & $* *$ & $* *$ & $* *$ & $* *$ & $*$ & $*$ & $*$ & $* * *$ & $* *$ \\
\hline Location $\times$ Shade & NS & NS & NS & $* *$ & $* *$ & $*$ & $*$ & NS & NS & NS & $* *$ & $*$ \\
\hline
\end{tabular}

${ }^{\mathrm{z}} \mathrm{NS}, *, * * * * *$ Nonsignificant or significant at $P \leq 0.05, P \leq 0.01$, or $P \leq 0.001$, respectively.

the north side of rows that were oriented east-west (Manuel Jimenez, personal communication). A large grower in California is growing 'Ouachita' [11], 'Natchez' [12] and 'Prime-Ark 45' [13] blackberries under high tunnels clad with a 50\% shade cloth in attempt to reduce white drupe formation (personal observation). A study was initiated with cooperators at North Carolina State University in 2011 to evaluate the fruit quality of 'Natchez', 'Ouachita', and soon-to-be released NC-430 blackberries trained on the RCA trellis in rows oriented north-south and east-west with fruit positioned on east, north, west, or south side of plant canopy (http://teamrubus.blogspot.com/2012/08/rotatingcross-arm-trellis-august-update.html). This study should lead to a better understanding of the effects of solar radiation and temperature on white drupe disorder in blackberry.

\section{Alternative blackberry propagation methods}

Blackberry has been traditionally propagated using tip layering, cane (soft and hard) and root cuttings, and tissue culture. Recently, we reported on simple, inexpensive methods for propagating blackberry plants by hardwood or floricane stem cuttings [2-6]. When the RCA trellis and cane training system was used, three- to five-times more propagation material from stock plants than with traditional methods was produced. A method for root and flower shoot induction in one-node floricane cuttings was achieved just by placing cuttings in plastic bags with moistened paper towel [9]. It has the potential to generate 3200 miniature plants from each stock plant and transplants that will fruit in just 2 or 3 months after delivery. This makes them attractive as house plants and for growing of fresh berries within the confines of controlled environment cropping systems. Collaboration with the University of Arizona Controlled Environment Agriculture is being pursued to develop production systems for growing miniature blackberry as a source of fresh fruit on Antarctica or even on the moon!

Tip-layering is laborious and the ratio of new transplants produced from each stock plant is usually low. With the RCA trellis and cane training system, 25 or more long cane plants to stock plant ratio has been possible [8]. Lateral canes that develop from horizontally trained primocanes can be trained to grow upward on the wires positioned on the slanted cross-arms (Fig. 8). Once these lateral canes grow beyond the top wire they grow downward. By mid August, laterals reach $\sim 3-\mathrm{m}$ in length with the tips of lateral canes extending down to the ground. Tips can be inserted into pots to induce adventitious root development. In the moistened media, rooting occurred in less than two weeks.

We produced both long-cane and looped-cane plants using the RCA trellis technology. Long-cane plants were produced by detaching the distal half of lateral cane in late September from the stock plant at point B as shown in Fig. 8. After the distal section was removed from the stock plant, the cross-arms were rotated counter-clockwise so that the cut ends of basal half of lateral canes (point B as shown in Fig. 8) was near ground and could be inserted 


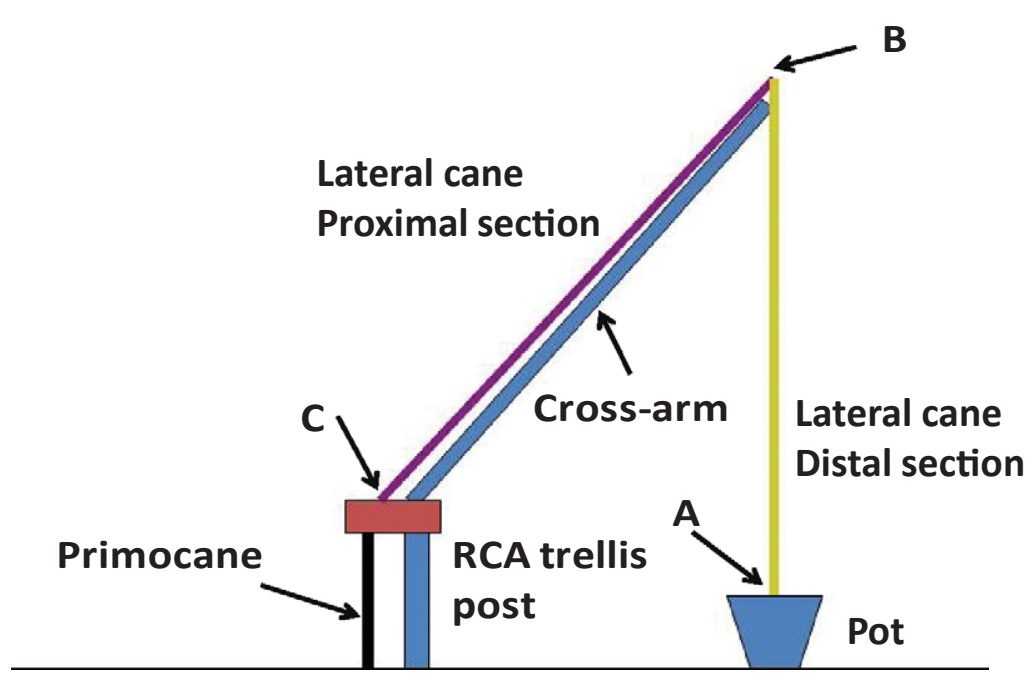

Fig. 8. Schematic drawing showing the method of producing canes plants from lateral canes trained on the rotating cross-arm trellis system. The distal end of 4-m-long lateral cane was inserted into a pot (A). Long-cane plants were produced by detaching the distal half of lateral cane in late September from the stock plant at point B. Looped-cane plants were produced by detaching the lateral cane at point $\mathrm{C}$ after rooting the tip (A) and then inserting the cut end $(\mathrm{C})$ into a rooting medium. Roots developed at the proximal end of the lateral cane. Refer to Fig. $4 \mathrm{C}$ for details of lateral canes originating from horizontally oriented primocanes on the RCA trellis.

into rooting medium. The intent was to produce long-cane plants from basal half of lateral canes. However, rooting was poor or none at the distal end of basal half of lateral canes (e.g. point B). Lower temperatures in October and November may not have been conducive for root development.

Instead of trying to produce two long-cane plants from each lateral cane, it was decided to detach the entire lateral canes from the stock plant in late September once adequate root mass had formed in the pot. When the basal ends of 3-m long lateral canes (e.g. Point $\mathrm{C}$ in Fig. 8) were then inserted into a moistened medium, rooting occurred at that end as well. With this procedure, 3-m-long cane plants with roots at both ends of the cane were generated (e.g. "looped" cane plants) (Fig. 9A). A provisional patent application (United States Patent and Trademark Office application No. 12/887, 851) was filed on 9 Sept. 2010 with the United States Patent and Trademark Office for producing long-cane plants using the RCA trellis technology.

Both long-cane and looped cane plants of 'Siskiyou' and 'Triple Crown' blackberry were held in a unheated greenhouse until December after which they were transferred to temperature controlled growth chambers maintained at 17 to $22^{\circ} \mathrm{C}$ during day and 14 to $16^{\circ} \mathrm{C}$ at night. A comparison of the data on growth and development variables of long-cane and looped cane plants of 'Siskiyou' and 'Triple Crown' blackberry are presented in Table 2.

In both cultivars, about $70 \%$ of axillary buds pushed or broke, however inflorescences developed on 68 and $46 \%$ of shoots on 'Siskiyou' and 'Triple Crown' cane plants, respectively. Among the field-grown, mature plants of these two cultivars, inflorescences typically developed on similar number of axillary buds (4). Our results indicate that detachment of lateral canes from the stock after adequate rooting had occurred at the distal end did not adversely affect the reproductive potential of long-cane plants.

Yield components were significantly affected by the production method used to produce long-cane plants. Specifically, clusters $\cdot \mathrm{m}^{-1}$ cane length, flowers per cluster, and fruit size on looped cane plants was increased 50, 15, and $22 \%$, respectively, compared to that of tall-cane plants (Table 2). Whether the basal half of lateral canes was more productive than the distal half of lateral canes or having roots at both ends of canes contributed to increase yield potential for looped cane plants require further research. In addition, questions remains whether cutting the lateral cane at the top of the loop to make two long-cane plants to aid in their transport to the fruiting field would affect their productivity. The cultivar $\times$ system interaction for the variables affecting potential yield was not significant. 


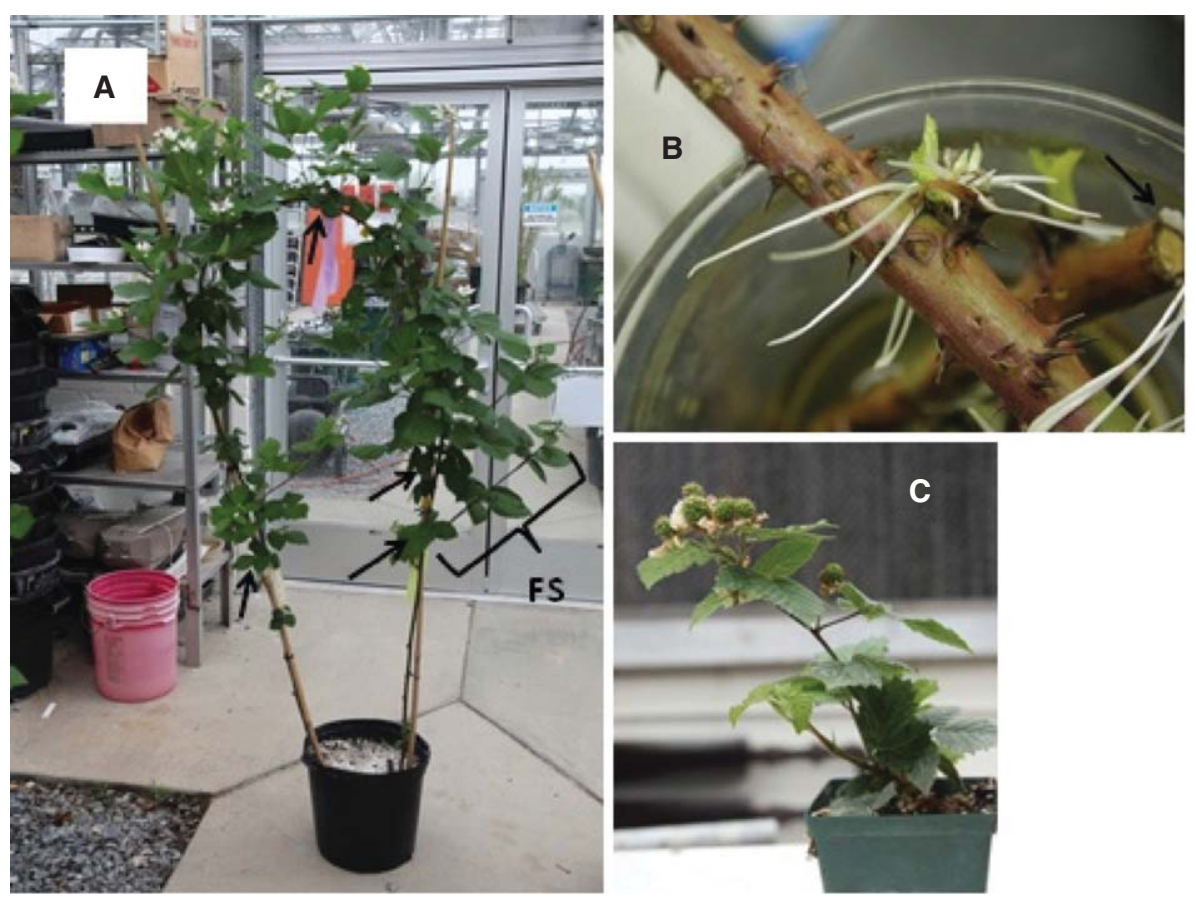

Fig. 9. Unique plant material produced from canes trained to the rotating cross-arm trellis for fruit production in out-of-season or protected environment agriculture. Plants were produced by vegetative propagation method using floricane cuttings. A) Looped cane plants with roots at both ends of the 4-m long lateral cane. Long cane plants produced with roots at both ends were more productive than long-cane plants rooted at the distal end. Lateral canes were harvested in winter and made into one-node cuttings. Winter-propagated looped cane plants possessed leaves that were produced the previous summer (arrows). A flower shoot (FS) developed from axillary buds subtended by a leaf. B) One-node cutting with roots initiating at the node. Callus developed at the cut end (arrow). C) Miniature blackberry plant produced from one-node floricane cutting. Typically these plants developed a one flower/fruit shoot with 5 to 10 berries. Also a primocane (vegetative shoot) emerged from the node. The plant is growing in a $10-\mathrm{cm}$ square pot.

Table 2

The effect of cultivar and long cane tip layering propagation method (long canes or looped canes) on the number of nodes per cane, the percentages of nodes to reach green tip, and produce flowers, the mean number of flowers per cluster, and mean berry weight of 'Triple Crown' and 'Siskiyou' blackberry in 2012

\begin{tabular}{|c|c|c|c|c|c|}
\hline Treatment & Nodes/cane (no.) & Budbreak (\%) & Nodes with flower shoot (no.) & Flowers/cluster (no.) & Berry wt. (g) \\
\hline \multicolumn{6}{|l|}{ Cultivar } \\
\hline Triple Crown & $37 b^{z}$ & $70 \mathrm{a}$ & $12 \mathrm{~b}$ & $7.0 \mathrm{a}$ & 6.7 \\
\hline Siskiyou & 57 a & 69 a & $23 \mathrm{a}$ & $3.1 \mathrm{~b}$ & 6.2 \\
\hline \multicolumn{6}{|l|}{ System } \\
\hline Long Canes & $32 \mathrm{~b}$ & $64 \mathrm{~b}$ & $10 \mathrm{~b}$ & $4.6 \mathrm{a}$ & $5.8 \mathrm{~b}$ \\
\hline Looped Canes & 62 a & $74 \mathrm{a}$ & $26 \mathrm{a}$ & $5.3 \mathrm{~b}$ & $7.1 \mathrm{a}$ \\
\hline \multicolumn{6}{|l|}{$\operatorname{Pr}>F$} \\
\hline Cultivar & 0.0001 & 0.8443 & 0.0266 & 0.0056 & 0.1263 \\
\hline System & 0.0001 & 0.0033 & 0.0001 & 0.0001 & 0.0002 \\
\hline Cultivar $\times$ System & 0.0001 & 0.0005 & 0.2240 & 0.3047 & 0.5062 \\
\hline
\end{tabular}

${ }^{\mathrm{z}}$ Mean within a column and cultivar or system followed by the same letter do not differ according to $T$-test $(P<0.05)$. 
The method of producing long-cane plants using the RCA trellis appears to generate more transplants than the quantities possible with traditional tip-layering or from high-density plantings of TC container plants system. The research to date on using the RCA trellis system for production of long-cane plants has evaluated plant performance after a short period to cold temperatures for early season fruit production in protected environment. Additional studies are needed to determine the effect of longer exposure to cold temperatures and dark, cold-room storage on the performance of long-cane blackberry plants. The cold-stored, containerized long-cane blackberry plants have potential for late-season fruit production.

As previously described, the RCA technology allows each stock plant to produce tremendous amount of lateral canes that are relatively straight in a narrow canopy. Lateral canes that are developed in this manner are easily to prune/harvest in winter to produce cuttings. An enclosure technique was developed to promote adventitious root development in floricane cuttings [9]. In a moist environment, cuttings developed callus at the cut ends, but the adventitious roots appeared at the base of the axillary bud (Fig. 9B). Once several adventitious roots were about 3$\mathrm{cm}$ long, the cuttings were transplanted into 10-cm square pots and moved to a heated greenhouse (Fig. 9C). Flowers opened in about 1 month and fruit ripened in about 55 days. It is anticipated that the effectiveness, efficiency, and low cost of this enclosure approach can be used for large- and small-scale propagation of blackberry plants. The use of one-node cuttings for the enclosed system maximized the quantity of cuttings that could be obtained from stock plants. Looped-cane and miniature plant material developed through our research offer opportunities to grow blackberries in areas with inadequate winter chilling for satisfactory blackberry production and in a high-density system under controlled environment for out-of-season fruit production. However, some modifications to stock plant production technique maybe necessary to comply with clean-plant certification program.

\section{Technology transfer effort to expand blackberry production}

Recent studies showed that the combination of laying lateral canes close to the ground and covering the plants with rowcover during the winter protected blackberry plants from freezing temperatures $[4,6]$. The fact that the RCA trellis and cane training system allows the lateral canes to be positioned horizontally with ease has stimulated blackberry production in the northcentral (Oklahoma, Kansas, Iowa, Missouri, Illinois, Indiana, Ohio) and in the northeastern US (Pennsylvania, New York, New Jersey, Maryland, and Massachusetts). In the last two years, nearly 100 ha of new blackberry plantings have been established with the RCA trellis system in the US.

Trellis Growing System (TGS), received USDA National Institute for Food and Agriculture Small Business Innovation Research program Phase I and II grants (http://www.trellisgrowingsystems.com/resources/RCA Trellis.pdf) for commercializing and marketing the RCA technology and related fiberglass-component RCA trellis. TGS reported that from 2010 to 2012 it had sold RCA trellises to commercial blackberry growers (size ranging from 0.4 to 10-ha) in more than 30 states. ARS and Trellis Growing Systems are collaborating with North Carolina State University, Iowa State University, and the University of California to study the effects of row orientations and fruit locations in plant canopy on sun-related injury and to determine whether growing blackberries on the RCA trellis can increase fresh pack-out by reducing sunburn damage in blackberry cultivars such as 'Apache', 'Natchez' and 'Ouachita' [11, 12]. Also, ARS has collaborative efforts in Pennsylvania and Iowa to determine whether the production areas for new blackberry cultivars such as 'Onyx' [14] and soon-to-be-named US-OSU 1939-4 and 1793-1 from USDA-ARS blackberry breeding program in Corvallis, OR can be expanded to the mid-Atlantic coast region and the northcentral US using the RCA trellis and cane training system. Other efforts are underway to improve winter survival of eastern thornless 'Chester Thornless' and 'Triple Crown' blackberry and 'Natchez' and 'Ouachita' blackberry in USDA Plant Hardiness Zone 5 ( $<-23^{\circ} \mathrm{C}$ minimum winter temperatures).

\section{Some physiological implications of novel blackberry production systems}

Many leaves on tall cane plants as well as on canes of field-grown plants under the floating row cover did not abscise and remained green until spring. Temperature measurements recorded in November, December, and January showed that on several nights the temperature had dropped below $-12^{\circ} \mathrm{C}$. Photosynthetic measurements of these overwintered 
Table 3

Net carbon exchange rate $\left(\mu \mathrm{mol} \cdot \mathrm{m}^{-} 2 \cdot \mathrm{s}^{-1}\right)$ and chlorophyll fluorescence ratio $(\mathrm{Fv} / \mathrm{Fm})$ in over-wintered, green leaves at the axils of long-cane plants and leaves on the flower shoots that emerged in spring from axillary buds on long-cane plants. Measurements were taken from leaves on long-cane plants of 'Siskiyou' and 'Triple Crown' blackberry. The cultivar effect was significant, but there was no significant difference between new and old leaves so they were pooled

\begin{tabular}{|c|c|c|c|c|c|}
\hline \multirow[t]{3}{*}{ Cultivar } & \multicolumn{4}{|c|}{ Net carbon exchange rate $\left(\mu \mathrm{mol} \cdot \mathrm{m}^{-} 2 \cdot \mathrm{s}^{-1}\right)$} & \multirow{3}{*}{$\begin{array}{c}\text { Chlorophyll } \\
\text { fluorescence } \\
(\mathrm{Fv} / \mathrm{Fm})\end{array}$} \\
\hline & \multicolumn{4}{|c|}{ Photosynthetic photon flux $\left(\mu \mathrm{mol} \cdot \mathrm{m}^{-} 2 \cdot \mathrm{s}^{-1}\right)$} & \\
\hline & 0 & 500 & 1000 & 1500 & \\
\hline Siskiyou & $1.1 \mathrm{a}^{\mathrm{z}}$ & $7.5 \mathrm{~b}$ & $8.2 \mathrm{~b}$ & $10.8 \mathrm{~b}$ & $0.8374 \mathrm{a}$ \\
\hline Triple crown & $0.1 \mathrm{~b}$ & $14.3 \mathrm{a}$ & $12.8 \mathrm{a}$ & $13.4 \mathrm{a}$ & $0.8145 \mathrm{a}$ \\
\hline
\end{tabular}

${ }^{\mathrm{z}}$ Mean within a column followed by the same letter do not differ according to $T$-test $(P<0.05)$.

leaves and new spring leaves that developed on flowering shoots were taken in April 2012. Photosynthetic data were collected using a portable $\mathrm{CO}_{2}$ gas analyzer (PP Systems, Amesbury, MA) with an integrated light source to maintain constant light, temperature, and $\mathrm{CO}_{2}$ during measurements. Light response curves were generated using light levels between 0 and $1,500 \mu \mathrm{mol} \cdot \mathrm{m}^{-2} \cdot \mathrm{s}^{-1}$ made on the center leaflet of fully expanded leaves. $\mathrm{CO}_{2}$ concentration was set at $400 \mu \mathrm{mol} \cdot \mathrm{mol}^{-1}$ with a flow rate of $0.10 \mathrm{~L} \cdot \mathrm{min}^{-1}$. Leaf temperature in the cuvette was maintained at $25^{\circ} \mathrm{C}$. In addition, chlorophyll fluorescence was measured to calculate the ratio of variable to maximum fluorescence $\left(\mathrm{F}_{\mathrm{v}} / \mathrm{F}_{\mathrm{m}}\right)$ using a portable chlorophyll fluorometer (Hansatech Instruments, Norfolk, United Kingdom).

Results of the single leaflet measurements showed that the net carbon exchange rate (NCER) was similar for over-wintered and spring-emerged leaves of 'Siskiyou' and 'Triple Crown' blackberries and in both leaf types the net photosynthetic rate was relatively high over the range of 500 to $1500 \mu \mathrm{mol} \cdot \mathrm{m}^{-2} \cdot \mathrm{s}^{-1}$ (Table 3). Chlorophyll fluorescence measurements showed that the $\mathrm{F}_{\mathrm{v}} / \mathrm{F}_{\mathrm{m}}$ ratio for over-wintered and spring-emerged leaves was 0.8374 and 0.8145 , respectively. Fv/Fm ratio estimates the potential efficiency of PSII if all capable reaction centers are open. An Fv/Fm value in the range of 0.79 to 0.84 is considered the approximate optimal value for mature leaves [15]. When plants are exposed to abiotic stresses in the light, decreases in Fv/Fm are frequently observed. These results highlighted the fact that leaves on floricanes, if over-wintered under certain conditions, remained $\mathrm{F}_{\mathrm{v}} / \mathrm{F}_{\mathrm{m}}$ functional over a long period of time and maintained a satisfactory NCER. The ability of leaves to efficiently photosynthesize in low light levels under the floating rowcover in winter should be beneficial to the blackberry plants. Further study of quantum yield, and dark respiration rates, related to degree of winter injury in blackberries in open and under rowcover would allow greater understanding of bud and cane survival under harsh winter conditions.

Recently, Takeda et al. [9] described a simple technique for inducing adventitious root development at the base of axillary buds on the non-leafy, floricane cuttings of several blackberry cultivars. Adventitious root development was abundant in floricane cuttings of 'Siskiyou', intermediate in 'Triple Crown', but none in floricane cuttings of 'Apache' blackberry. We hypothesized that the endogenous auxin concentration of the axillary buds might differ among these cultivars.

For this study, explants ( 1 to $3 \mathrm{~cm}$ long cane segments, each with one bud) of 3 blackberry cultivars ('Siskiyou', 'Triple Crown' and 'Apache') were removed from field-grown blackberry and 3 replicates (10 buds per replicate) were collected. At time 0, half the buds were cut so as to remove the top half of the bud (decapitation) and the remaining explants were retained with intact buds (intact). The retained explants were maintained for 2 weeks at room temperature in a dark, high-humidity environment. At 2 weeks, rooting was measured and the buds were sampled.

Selected buds were quickly frozen, lyophilized, ground and analyzed for indole-3-acetic acid (IAA) [16]. A $200 \mathrm{mg}$ sample was extracted in a solution of $80 \%$ methyl alcohol, $20 \% \mathrm{H}_{2} \mathrm{O}, 16 \mathrm{mg} / \mathrm{l}$ butylated hydroxytoluene, $10 \mathrm{mg} / \mathrm{l}$ ascorbic acid. Known quantities of ${ }^{13} \mathrm{C}_{6}$-IAA were added to determine percent recovery through the extraction and purification process. Extracts were purified using PVPP and high load $\mathrm{C}_{18}$ columns. Column purified extracts were then flash evaporated, dissolved in $100 \%$ methanol, dried under streaming $\mathrm{N}_{2}$, derivatized with ethereal diazomethane and re-suspended in ethyl acetate. IAA was quantified by GC/MS with a $30 \mathrm{~m}$ DB-5 (Agilent) coated glass capillary column with a temperature gradient initiating at $60^{\circ} \mathrm{C}$, ramped at $5^{\circ} \mathrm{C} \cdot \mathrm{min}^{-1}$ to $200^{\circ} \mathrm{C}$ in 30 minutes, ramped at 
$30^{\circ} \mathrm{C} \cdot \min ^{-1} \min$ to $300^{\circ} \mathrm{C}$ and then held for 10 minutes. MS acquisition mode was selective ion monitoring for 130 , 136, 189, 195 atomic mass units targeting native and stable isotope IAA ions from 20 to 27 minutes. Standard curve regression was used to determine unknown sample quantities based on peak area and compound identity was verified by retention time and mass spectrum.

A second study was performed which consisted of two bud treatments (intact buds at 0 and 2 weeks and decapitated buds at 2 weeks); 3 varieties ('Siskiyou', 'Triple Crown' and 'Apache'); 10 buds per replicate; and 3 replicates for a total of 27 experimental units with 10 buds per experimental unit. The entire experiment was performed twice in December 2010 and March 2011.

Differences between experiments were not significant and interaction means were not significantly different from each other. The main effects of decapitating buds were not significant. IAA concentrations were different among the three cultivars. Initial IAA concentration in 'Triple Crown' $(14 \mathrm{nmol} / \mathrm{g})$ buds was greater than in either 'Apache' $(2.2 \mathrm{nmol} / \mathrm{g})$ or 'Siskiyou' $(4.3 \mathrm{nmol} / \mathrm{g})$ buds. At 2 weeks after decapitation, 'Siskiyou' $(3.5 \mathrm{nmol} / \mathrm{g})$ buds had significantly greater IAA concentration than 'Triple Crown' $(2.0 \mathrm{nmol} / \mathrm{g})$ buds. 'Apache' buds had an intermediate level of IAA. No significant differences among intact buds of these three cultivars were detected (e.g. overall mean of $2.5 \mathrm{nmol} / \mathrm{g})$.

Although 'Triple Crown' blackberry buds had higher IAA concentrations at the start of each experiment, the concentration was significantly reduced after 2 weeks. 'Siskiyou' blackberry buds had the highest concentration at 2 weeks. This observation showed this cultivar had produced greater numbers of adventitious roots during that time, indicating a possible link between IAA concentrations and root induction in floricane cuttings. In previous work [14], more budbreak and greater rooting was associated with 'Siskiyou' than with 'Triple Crown' blackberry. The enclosure technique worked well for some cultivars, but it must be refined to improve rooting of recalcitrant cultivars like 'Apache' blackberry. Our findings suggest that additional studies are warranted to better understand the contribution of genetic component in adventitious root formation and budbreak and the relationships between endogenous plant growth regulators, rooting, and budbreak.

\section{Conclusion}

Studies were conducted to determine the efficacy of novel cultural treatments to mitigate low winter temperature and high light intensity on cane mortality and fruit quality, respectively. These new strategies have enabled blackberry production to expand into areas with more severe winter conditions than those that occur in traditional production areas and improve blackberry fruit quality. In addition, the research and development effort at the Appalachian Fruit Research Station over the last two decades on alternative production systems and evaluation of blackberry cultivars has provided a new knowledge base to increase capacity and efficiency in blackberry cultivation. New production technology and techniques have fostered niche market blackberry production and have created opportunities to produce blackberries in areas with severe winter conditions. New propagation strategies have been developed for producing miniature plants that flower soon after rooting and for increasing the output of long-cane plants. Research has provided a better understanding of plant material source and environmental conditions during the vegetative propagation phase that affect rooting and reproductive capacity among several blackberry cultivars. Plant material developed through our research offer opportunities to grow blackberries in new environments, under different climates, and for out-of-season production.

Technology transfer efforts based on our applied and basic research have contributed to improving viability of small fruit farming and rural vitality in several regions of the US. The development of partnership with commercial-sector partners has accelerated the adoption of USDA-developed technology by the blackberry industry and has helped to gain additional funds to supplement in-house research support. For example, Trellis Growing Systems has taken to the marketplace improved and manufactured components for the USDA-developed RCA trellis technology that allows growers to achieve quicker return on their investment. Additional research on production systems and evaluation of new blackberry cultivars are needed to 1) foster expansion of blackberry industry into the northern region of the US, 2) and to make this segment of the blackberry industry a significant supplier of high quality blackberry fruit, and 3) improve the competitiveness of the northern region of the US with other major blackberry production areas, such as Mexico, California, the Pacific Northwest, and southeastern US. 


\section{Acknowledgments}

This work was funded by the Agricultural Research Service of the US Department of Agriculture (CRIS Project No. 1931-21000-018D). Additional support came from USDA-National Institute of Agriculture and Food through its Small Business Innovation Research grant program (Grant No. 2008-00127 and 2009-01138) and from Trellis Growing Systems (USDA-ARS Agreement No. 58-1931-0-003). An appreciation is extended to the technical staff at the Appalachian Fruit Research Station, and especially to Ann Rose and Scott Wolford, for their many years of able assistance to the project. The authors also thank B. Strik, C. Finn, and G. Fernandez for providing blackberry production statistics for Oregon and North Carolina.

\section{References}

[1] Strik BC, Clark JR, Finn CE, Bañados MP. Worldwide blackberry production. HortTechnology. 2007;17:205-13.

[2] Takeda F, Peterson DL. Mechanical harvester, trellis designs, and cane training for eastern thornless blackberry production. Proc $1966 \mathrm{~N}$ Amer Bramble Growers Assoc Conf., (1996), 38-46. Available upon request from the author.

[3] Takeda F, Peterson DL. Considerations for machine harvesting fresh-market eastern thornless blackberries: Trellis design, cane training systems, and mechanical harvester development. HortTechnology. 1999;9:16-21.

[4] Takeda F, Demchak K, Warmund MR, Handley DT, Grube R, Feldhake C. Row covers improve winter survival and production of western trailing 'Siskiyou' blackberry in the eastern United States. HortTechnology. 2008;18:75-82.

[5] Takeda F, Phillips J. Horizontal cane orientation and rowcover application improve winter survival and yield of trailing 'Siskiyou' blackberry. HortTechnology. 2011;21:170-5.

[6] Takeda F. Innovating blackberry production systems. The Bramble (newsletter of North American Raspberry and Blackberry Growers Association, Pittsboro, NC). 2012;27:12-4.

[7] USDA Plant Hardiness Zone Map (2012). http://planthardiness.ars.usda.gov/PHZMWeb. Last accessed 25 May 2012.

[8] Takeda F, Soria J. Method for producing long-cane blackberry plants. HortTechnology. 2011;21:563-8.

[9] Takeda F, Tworkoski T, Finn C, Boyd C. Blackberry propagation by non-leafy floricane cuttings. HortTechnology. 2011;21:236-9.

[10] Finn CE, Yorgey BM, Strik BC, Harvey HK, Martin RR, Qian M. 'Black Diamond' thornless trailing blackberry. HortScience. 2005;40: 2175-8.

[11] Clark JR, Moore JN. 'Ouachita' thornless blackberry. HortScience. 2005;40:258-60.

[12] Clark JR, Moore JN. 'Natchez' thornless blackberry. HortScience. 2008;43:1897-9.

[13] Clark JR, Perkins-Veazie P. 'APF-45' primocane-fruiting blackberry. HortScience. 2011;46:670-3.

[14] Finn CE, Strik BC, Yorgey BM, Martin RR. 'Onyx' trailing blackberry. HortScience. 2011;46:657-9.

[15] Maxwell K, Johnson GN. Chlorophyll fluorescence - a practical guide. J Experimental Botany. 2000;51:659-68.

[16] Tworkoski T, Miller S. Endogenous hormone concentrations and bud-break response to exogenous benzyl adenine in shoots of apple trees with two growth habits grown on three rootstocks. Journal of Horticultural Science \& Biotechnology. 2007;82:960-6. 